\title{
FORMULATION AND EVALUATION OF NEW MEDICATED CHEWING GUM FOR THE TREATMENT OF NAUSEA AND VOMITING INDUCED BY CHEMOTHERAPY, RADIATION THERAPY, AND POST-OPERATIVE CONDITIONS IN CANCER
}

\author{
LALL DIPESH $^{1 *}$, RATHOR SHRUTI ${ }^{2}$, SONI PRANAY ${ }^{3}$ \\ ${ }^{1}$ Department of Pharmaceutics, School of Pharmacy, Chouksey Engineering College, Bilaspur, Chhattisgarh, India. ${ }^{2}$ Department of \\ Pharmaceutics, LCIT School of Pharmacy, Bilaspur, Chhattisgarh, India. ${ }^{3}$ Department of Pharmacology, LCIT School of Pharmacy, Bilaspur, \\ Chhattisgarh, India. Email: drshrutirathor@gmail.com
}

Received: 11 January 2020, Revised and Accepted: 25 February 2020

ABSTRACT

Objective: The objective of the present study was formulation and evaluation of new medicated chewing gum for the treatment of nausea and vomiting induced by chemotherapy, radiation therapy, and post-operative conditions in cancer using ondansetron hydrochloride as drug candidate.

Methods: The medicated chewing gum of ondansetron hydrochloride (OHC) was prepared by direct compression mold method. Four formulations were selected for study which was showing good physicochemical properties and drug release. Formulations were characterized for physical evaluation, weight variation, stickiness, hardness/plasticity, in vitro drug release, estimation of chewing gum consistency and drug release study in saliva.

Results: All the formulations gave satisfactory results in physical evaluation, weight variation, stickiness, and hardness. The formulation medicated chewing gum II (MCG II) showed best in vitro drug release which is $97 \%$ in $30 \mathrm{~min}$ and it is also more accepted by the people. Drug release in saliva also indicated that more than $50 \%$ drug release occurs within $15 \mathrm{~min}$.

Conclusion: Medicated chewing gum is a cost-effective product and also showed better compliance and increase in bioavailability.

Keywords: Ondansetron hydrochloride (OHC), MCGs, Chemotherapy-induced nausea and vomiting, Radiation therapy-induced nausea and vomiting, Post-operative nausea and vomiting, Cancer, Chewing gum.

(c) 2020 The Authors. Published by Innovare Academic Sciences Pvt Ltd. This is an open access article under the CC BY license (http://creativecommons. org/licenses/by/4. 0/) DOI: http://dx.doi.org/10.22159/ajpcr.2020.v13i4.37094

\section{INTRODUCTION}

Medicated chewing is a new drug delivery system for the prevention and treatment of chemotherapy-induced nausea and vomiting (CINV), radiation therapy-induced nausea and vomiting (RINV), and also in postoperative nausea and vomiting (PONV) conditions. Drugs are usually formulated in variety of dosage forms like tablets, capsules, injections, inhalers and ointments etc. The oral drug delivery system is most acceptable route of drug administration due to ease of administration than other dosage forms. In addition to confectionary role, nowadays, chewing gum is also showing best and convenient drug delivery system due to rapid absorption of agents which can be absorbed by oral cavity. Medicated chewing gums are more accepted by the parents for children as comparison to tablets, capsules, or liquids. Medicated chewing gums are used to deliver drug locally or systemically. Drug can be release locally for the oral treatment or may be absorbed rapidly by oral mucosa for systemic conditions, leading to fast onset of action and bioavailability. This avoids first-pass metabolism and also metabolism in gastrointestinal tract [1-7].

Chewing gum drug delivery system is convenient, easy to administer anywhere, anytime, and its pleasant taste making it most patient acceptable dosage form [1]. Chewing gum usually consists of gum core, which may or may not be coated. There are three methods by which medicated chewing gum can be prepared (1) fusion method, (2) cooling, grinding, and tableting method, and (3) direct compression [8-10]. Chewing gum is defined by the European Pharmacopoeia and guidelines for pharmaceutical dosage forms issued in 1991 by the Committee for Medicinal Products for Human Use (CPMP) as "solid single-dose preparations with a base consisting mainly of gums that are intended to be chewed but not swallowed, providing a slow steady release of the medicine contained". According to the European Pharmacopoeia, $4^{\text {th }}$ edition, 2002 medicated chewing gum is intended to be chewed but not swallowed, providing a slow steady release of the medicine contained. According to the European Pharmacopoeia, $4^{\text {th }}$ edition, 2002 medicated chewing gum is intended to be chewed for a certain period of time, required to deliver the dose, after which the remaining mass is discarded. During the chewing process, the drug contained in the gum product is released from the mass into saliva and it could be absorbed through the oral mucosa or swallowed reaching the stomach for gastrointestinal absorption; thus, two absorption pathways are possible to introduce the active ingredient, giving rise to a systemic effect. Medicated chewing gum offers a wide range of advantages that make it an excellent alternative [11-14]. Ondansetron hydrochloride $(\mathrm{HCl})$ is the drug of choice to prevent nausea and vomiting that may cause by cancer surgery, chemotherapy, and radiation treatment. Oil-holding capacity $(\mathrm{OHC})$ is a competitive serotonin type 3 receptor

Table 1: MCGs with different concentrations of PVP, dextrose, and PEG-400

\begin{tabular}{llllll}
\hline S. No. & Ingredients/quantity & MCG I & MCG II & MCG III & MCG IV \\
\hline 1. & Ondansetron $\mathrm{HCl}$ & $4.0 \mathrm{mg}$ & $4.0 \mathrm{mg}$ & $4.0 \mathrm{mg}$ & $4.0 \mathrm{mg}$ \\
2. & Ascorbic acid & $0.2 \mathrm{~g}$ & $0.2 \mathrm{~g}$ & $0.2 \mathrm{~g}$ & $0.2 \mathrm{~g}$ \\
3. & Beeswax & $1.0 \mathrm{~g}$ & $1.0 \mathrm{~g}$ & $1.0 \mathrm{~g}$ & $1.0 \mathrm{~g}$ \\
4. & PVP & $4.5 \mathrm{~g}$ & $5.0 \mathrm{~g}$ & $5.5 \mathrm{~g}$ & $6.0 \mathrm{~g}$ \\
5. & Dextrose & $0.7 \mathrm{~g}$ & $0.8 \mathrm{~g}$ & $0.9 \mathrm{~g}$ & $1.0 \mathrm{~g}$ \\
6. & Peppermint oil & $0.5 \mathrm{ml}$ & $0.5 \mathrm{ml}$ & $0.5 \mathrm{ml}$ & $0.5 \mathrm{ml}$ \\
7. & PEG-400 & $0.8 \mathrm{~g}$ & $1.0 \mathrm{~g}$ & $1.2 \mathrm{~g}$ & $1.2 \mathrm{~g}$ \\
8. & Calcium carbonate & $0.5 \mathrm{~g}$ & $0.5 \mathrm{~g}$ & $0.5 \mathrm{~g}$ & $0.5 \mathrm{~g}$ \\
\hline PEG: & Polyethylene glycol, HCl: Hydrochloride, PVP: Polyvinyl pyrrolidone
\end{tabular}

PEG: Polyethylene glycol, HCl: Hydrochloride, PVP: Polyvinyl pyrrolidone 
Table 2: Texture analysis data of MCGs of drug

\begin{tabular}{|c|c|c|c|c|}
\hline \multirow[t]{2}{*}{ S. No. } & \multirow[t]{2}{*}{ Formulation code } & \multicolumn{3}{|l|}{ Texture analysis data } \\
\hline & & Hardness (mean max force) (g) & Firmness (mean max force) (g) & Springiness mean ratio (\%) \\
\hline 1. & MCG I & $1.121 \pm 0.10$ & $600.1 \pm 0.44$ & $6.421 \pm 0.27$ \\
\hline 3. & MCG III & $3.121 \pm 0.08$ & $889.7 \pm 0.35$ & $6.820 \pm 0.39$ \\
\hline 4. & MCG IV & $3.227 \pm 0.42$ & $920.5 \pm 0.64$ & $6.514 \pm 0.62$ \\
\hline
\end{tabular}

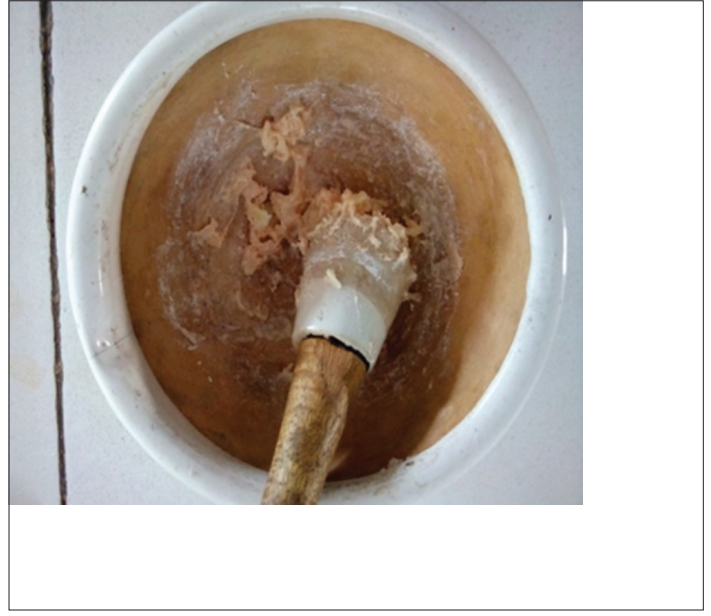

Fig. 1: Preparation of the MCGs

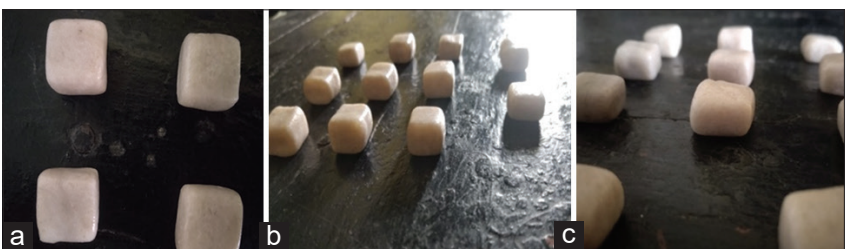

Fig. 2: (a) Formulated MCGs. (b) Formulated MCGs. (c) Formulated MCGs

antagonists and effective in the treatment of nausea and vomiting caused by cytotoxic agents. OHC blocks the actions of chemicals in the body that can also trigger nausea and vomiting. Having been developed in the 1980s by GlaxoSmithKline and approved by the USFDA since January 1991, OHC has demonstrated a long history of use and efficacy. Commonly formulated as oral tablets, orally disintegrating tablets, and injections and available as generic products as well, $\mathrm{OHC}$ continues to see contemporary innovations in its formulation and uses [15-19].

\section{MATERIALS AND METHODS}

\section{Materials}

Ondansetron $\mathrm{HCl}$ was a gift sample. Excipients polyvinylpyrrolidone (PVP), beeswax, dextrose, calcium carbonate, peppermint, ascorbic acid, and polyethylene glycol 400 (PEG-400) were of analytical or pharmaceutical grade were purchased.

\section{Method of preparation}

MCGs were prepared by direct compression mold method. In this method, each ingredient was weighed accurately and separately. OHC, PVP, beeswax, dextrose, calcium carbonate, peppermint oil, and ascorbic acid, all ingredients were thoroughly mixed in ascending order of their weights in a mortar. After proper mixing, ingredients smoothly grounded in a mortar pestle and then previously weighed quantity of PEG-400 were added. Then, the whole mixture was again mixed thoroughly in pestle mortar. After mixing and grinding, the mixture was subjected for compression into the desired molds and presses to form medicated chewing gum, as shown in Figs. 1 and 2a-c. After removing
Table 3: Drug content of medicated chewing gum

\begin{tabular}{lll}
\hline S. No. & Formulation & \% purity \\
\hline 1. & MCG I & 95.24 \\
2. & MCG II & 97.01 \\
3. & MCG III & 94.22 \\
4. & MCG IV & 94.84 \\
\hline
\end{tabular}

Table 4: Consistency study of medicated chewing gum

\begin{tabular}{lllllll}
\hline \multirow{2}{*}{ Formulation } & \multicolumn{2}{l}{ Volunteers } \\
\cline { 2 - 7 } & $\mathbf{1}$ & $\mathbf{2}$ & $\mathbf{3}$ & $\mathbf{4}$ & $\mathbf{5}$ & $\mathbf{6}$ \\
\hline MCG I & + & + & + & + & + & ++ \\
MCG II & ++ & +++ & +++ & +++ & ++ & ++ \\
MCG III & ++ & +++ & +++ & +++ & + & + \\
MCG IV & ++ & ++ & ++ & ++ & + & ++ \\
\hline
\end{tabular}

+: Acceptable, ++: Good, +++: Very good

from mold, formulated chewing gums were weighed and wrapped properly. Optimization of various selected batches of MCGs by changing concentration of different excipients is depicted in Table 1.

\section{Physical evaluation}

Physical properties such as size, shape, thickness, color, and odor must be evaluated. It is very important to investigate the MCGs physically, which plays a key role and these should not be disregarded, it is necessary for acceptance by individuals and even also in marketing [1].

\section{Weight variation test}

Weight variation plays an important role in evaluation parameters, it ensures that each of the medicated chewing gum contains the proper amount of dug. The test was carried out by weighing the 20 mediated chewing gum individually using analytical balance, then calculating the average weight, and comparing the individual medicated chewing gum to the average [1].

\section{Stickiness}

On plain surface, medicated chewing gum was placed, it is subjected to collide with Teflon hammer with mass of $250 \mathrm{~g}$ for a period of $10 \mathrm{~min}$. Hammering frequency was $30 / \mathrm{min}$. After specified time, amount of mass stick to hammer was observed and reported [1].

\section{Test for hardness/plasticity}

There is no one reported method for the determination of hardness; hence, it was decided to use Pfizer type hardness tester for the determination of hardness/plasticity of all MCG formulations [1].

\section{In vitro drug release studies}

A medicated chewing gum was immersed in $\mathrm{pH}$ solution maintained at pH 6.8 (buccal cavity) then placed on magnetic stirrer and subjected to stirring and after every $5 \mathrm{~min}$ interval $2 \mathrm{ml}$ of solution taken out and replaced with fresh buffer solution. Sample was withdrawn at regular intervals of $5,10,15,20,25$, and $30 \mathrm{~min}$. On completion of process, all the collected samples were UV spectrophotometrically analyzed on maximum wavelength of $310 \mathrm{~nm}$. 
Table 5: Cumulative percentage drug release of MCG II formulation in saliva

\begin{tabular}{llllllll}
\hline S. No. & Time (min) & \multicolumn{2}{l}{ \% drug release } & & & \\
\cline { 3 - 8 } & & Volunteer A & Volunteer B & Volunteer C & Volunteer D & Volunteer E & Volunteer F \\
\hline 1. & 0 & 0 & 0 & 0 & 0 & 0 & 0 \\
2. & 0.5 & $31.2 \pm 1.45$ & $31.5 \pm 2.01$ & $32.5 \pm 1.46$ & $32.7 \pm 2.08$ & $32.1 \pm 1.93$ & $32.1 \pm 1.74$ \\
3. & 1 & $34.9 \pm 1.94$ & $35.6 \pm 1.23$ & $36.6 \pm 1.84$ & $35.2 \pm 1.67$ & $35.8 \pm 1.07$ & $34.1 \pm 1.28$ \\
4. & 2 & $41.9 \pm 1.67$ & $39.5 \pm 2.23$ & $41.6 \pm 1.69$ & $41.5 \pm 2.05$ & $40.2 \pm 2.12$ & $42.0 \pm 1.90$ \\
5. & 5 & $43.4 \pm 2.31$ & $44.2 \pm 1.40$ & $42.7 \pm 1.98$ & $43.3 \pm 1.87$ & $43.4 \pm 1.06$ & $44.1 \pm 1.07$ \\
6. & 10 & $47.3 \pm 1.68$ & $48.31 \pm 1.58$ & $47.2 \pm 1.56$ & $47.9 \pm 1.52$ & $48.1 \pm 1.61$ & $49.0 \pm 1.83$ \\
7. & 15 & $52.4 \pm 1.23$ & $52.66 \pm 1.62$ & $53.2 \pm 1.73$ & $52.1 \pm 1.64$ & $53.6 \pm 1.37$ & $52.5 \pm 1.46$ \\
\hline
\end{tabular}

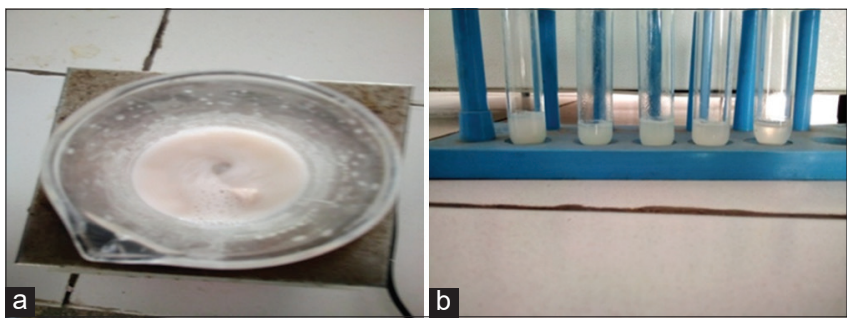

Fig. 3: (a) In vitro drug release study. (b) Ultraviolet spectrophotometric analysis of samples

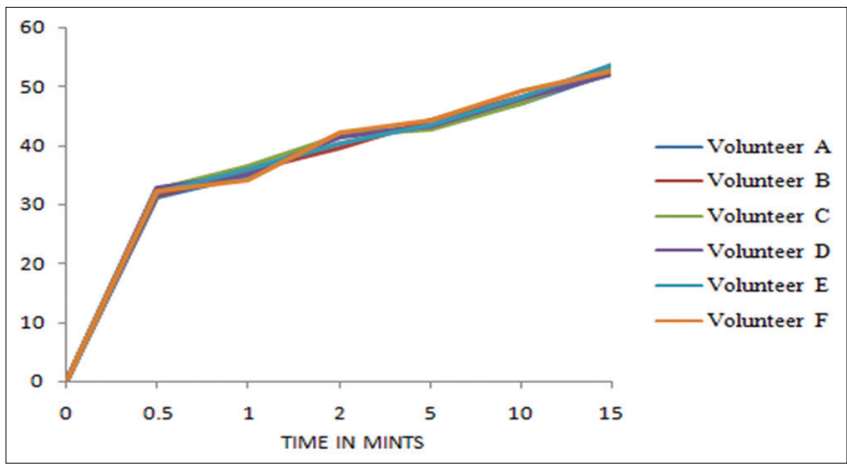

Fig. 4: Cumulative percentage drug release of MCG II formulation in saliva

\section{Estimation of chewing gum consistency}

This study was carried out using chew out method. Dummy chewing (without drug) was prepared according to optimized formula to check consistency. Then, they were given for certain human volunteer to chew it [11].

\section{Drug release study in saliva}

Medicated chewing gums are having quite different drug release process compared to conventional oral drug delivery system. In Medicated chewing gums not only dosage form but also chewing activity of patient may also affects the drug delivery. Mechanical treatment is required to deliver the drug by the teeth but not involve in dissolution. Release of drug from MCGs in saliva was studied by recruiting a panel of six members of volunteers and designed chew out studies. One sample was given to each volunteer for chewing for a particular time interval period, i.e., 0.5, 1, 2, 5, 10, and 15 min. After chewing, chewed out chewing gum samples collected from volunteer, stretched maximum, and cut into small pieces after that dispersed in a $100 \mathrm{ml}$ volumetric flask having phosphate buffer $\mathrm{pH}$ 6.8, which was then heated and sonicated for $10 \mathrm{~min}$. These samples were then analyzed by UV spectrophotometer at absorption maxima $310 \mathrm{~nm}$ for residual drug content in MCGs $[1,2]$.

Amount of drug release during mastication $=$ The total drug content Residual drug after chewing

\section{RESULTS AND DISCUSSION}

In the present work, an attempt was made to develop medicated chewing gum containing OHC drug. Formulation MCG II was selected as optimized formulation for making medicated chewing gums, where ascorbic acid was used as antioxidant, dextrose was used as sweetening agent as well as bulking agent, beeswax/PVP as elastomer and gum, peppermint oil was used as flavoring agent. Optimized formulation was physically evaluated having weight $5.5 \mathrm{~g}$, shape was cubic having thickness $1.4 \mathrm{~cm}$ with whitish-cream color and peppermint odor. Weight variations study revealed that all formulations are having weights in normal range. All formulations showed negligible stickiness and hardness also found within range, as shown in Table 2.

In vitro drug release, it was found that almost all formulations release more than $97 \%$ drug after 30 min. However, the optimized formulation MCG II has shown the best release as comparison to other formulations. Hence, it was selected for further study, Fig. 3a and b. The prepared formulations were analyzed for drug content and it was found that MCG II was having highest drug content, i.e., $97.01 \%$, as shown in Table 3. MCGs were studied for consistency on human volunteer and MCG II was more accepted by human volunteers data which are tabulated in Table 4.

Drug release study in saliva is shown in Fig. 4, cumulative percentage drug release in each individual is also given in Table 5, it was observed that within $15 \mathrm{~min}$, more than $50 \%$ of drug was released from the optimized formulation MCG II. This study revealed that the drug release was depended on the chewing frequency of the volunteer.

\section{CONCLUSION}

Medicated chewing gum $\mathrm{OHC}$ was successfully prepared. OHC is a potent and highly selective 5-HT3 receptor antagonist having important antiemetic activity and good tolerability. It is a cost-effective formulation and having better patient compliance and bioavailability. OHC is completely absorbed by GIT which makes this as a choice of drug in preparing medicated chewing gum of OHC. Due to hepatic first-pass metabolism, only $60 \% \mathrm{OHC}$ is bioavailable compared with IV route so this can be also avoided by preparing MCGs.

In vitro drug release study indicated that drug release from formulation MCG II is best among others so it is the best formulation than others. All the parameters found to be satisfactory; hence, the therapeutic dose of $\mathrm{OHC}$ can be given in medicated chewing gum with optimized formula, i.e., MCGII. This study concluded that it is possible to make medicated chewing of $\mathrm{OHC}$ for prevention and treatment of vomiting induced by CINV, RINV, and also in PONV conditions.

\section{AUTHORS' CONTRIBUTIONS}

Contribution of all authors is equal in this work.

\section{CONFLICTS OF INTEREST}

The authors declare that there are no conflicts of interest regarding the publication of paper. 


\section{SOURCE OF FUNDING}

Nil.

\section{REFERENCES}

1. Agrawal A, Sudhakar C. Design and development, characterization and in vitro evaluation of medicated chewing gum: Granisetron hydrochloride. J Drug Deliv Ther 2019;8:43-7.

2. Paradhkar M, Gajra B, Patel B. Formulation development and evaluation of medicated chewing gum of anti-emetic drug. Saudi Pharm J 2016;24:153-64

3. Wathore SA, Kale VK. Formulation and evaluation of medicated chewing gum of granisetron. Pharma Innov J 2019;898:283-6.

4. Hamdan H, Zaini S. Effect of nicotine on schizophrenia and antipsychotic medications: A systematic review. Malays J Psychiatry 2018;27:10-25.

5. Al Hagbani T, Altomare C, Salawi A, Nazzal S. D-optimal mixture design: Formulation development, mechanical characterization, and optimization of curcumin chewing gums using oppanol ${ }^{\circledR}$ B 12 elastomer as a gum-base. Int J Pharm 2018;553:210-9.

6. Wessel SW, van der Mei HC, Maitra A, Dodds MW, Busscher HJ. Potential benefits of chewing gum for the delivery of oral therapeutics and its possible role in oral healthcare. Expert Opin Drug Deliv 2016;13:1421-31.

7. Aslani A, Ghannadi A, Rostami F. Design, formulation, and evaluation of ginger medicated chewing gum. Adv Biomed Res 2016;5:130.

8. John A, Kumar K, Dinesh KB. Medicated chewing gum: Modern drug delivery system. Univers J Pharm Sci Res 2019;5:29-39.

9. Committee for Medicinal Products for Human Use. CPMP List of Allowed Terms for the Pharmaceutical Dosage Form, Route of
Administration, Container, Closure and Administration Devices. Brussels, Belgium: Commission of the European Communities; 1991.

10. Dabhi P, Jivani NP. Development and validation of a selective analytical hplc method for the quantification of guaifenesin in guaifenesin medicated chewing gum intended for cough relief. Int J Eng Sci Comput 2019;9:22643-9.

11. Vagada R, Seth AK, Sachin C, Parikh P, Kheini P, Chainesh S, et al. Formulation and evaluation of novel gum based drug delivery system of an antiemetic drug. Int J Pharm Res Technol 2012;2:16-20.

12. Nazzal S, Bratbak G. Medicated chewing gums (MCG's): Composition production and mechanical testing. AAPS Pharm Sci Technol 2018;2:1-13.

13. Konar N, Sagdic O, Toker OS, Palabiyik I. Chewing gum: Production, quality parameters and opportunities for delivering bioactive compounds. Trends Food Sci Technol 2016;55:29-38.

14. Shaikh A, Agrawal A, Gupta M. Formulation and evaluation of medicated chewing gum of dolasetron as an antiemetic agent. J Drug Deliv Ther 2017;7:125-8.

15. Ondansetron Hydrochloride. Drug Bank. Available from: https://www. drugbank.ca/drugs/db00904

16. Gupta M, Dahiya J, Marwaha RK, Dureja H. Therapies in cancer treatment: An overview. Int J Pharm Pharma Sci 2015;7:1-9.

17. Pramila P, Abraham A, Pawar S, Bafna V, Bansal MS. To study the therapeutic management, drug related problems and concomitant use of drugs in patients with cancer. Int J Pharm Pharma Sci 2017;9:139-44.

18. Simons D, Beighton D, Brailsford R. The effect of medicated chewing gums on oral health in older people: A one year clinical trials. J Am Geriatr Soc 2010;50:1348-53.

19. Mustafa W, Muniz G. The impact of chewing gums of eucalyptus extract: A systematic review. J Breath Res 2017;11:14-20. 